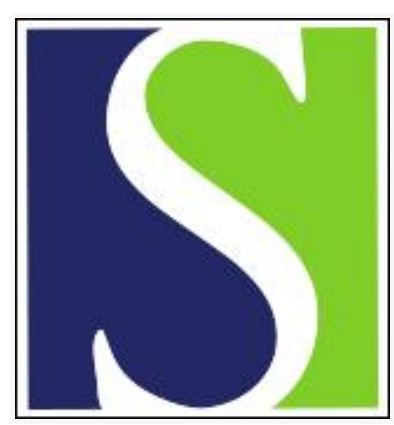

Scand J Work Environ Health 1984;10(6):429-433

https://doi.org/10.5271/sjweh.2301

Issue date: Dec 1984

Arthrosis and its relation to work.

by Anderson JA

This article in PubMed: www.ncbi.nlm.nih.gov/pubmed/6535245

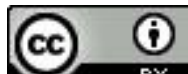

This work is licensed under a Creative Commons Attribution 4.0 International License 


\title{
Arthrosis and its relation to work
}

\author{
by John AD Anderson, MD, FFCM
}

\begin{abstract}
ANDERSON JAD. Arthrosis and its relation to work. Scand J Work Environ Health 10 (1984) 429433. Data are presented to illustrate the inadequacy of routinely collected data on osteoarthrosis when disability and handicap are considered as distinct from impairment. In a series of prevalence studies of mixed manual workers aged 15 to 65 years in the United Kingdom $11 \%$ had diagnosable osteoarthrosis of the limbs, $2 \%$ had generalized osteoarthrosis, and $11 \%$ had vague pains of undetermined diagnosis in the limb joints. Annual sickness absence was $580 \mathrm{~d} / 100$ affected men for those with local osteoarthrosis and $539 \mathrm{~d} / 100$ and $80 \mathrm{~d} / 100$, respectively, for those with generalized osteoarthrosis and vague limb pain. These and other indicators of disablement (hospital attendance and admission, self therapy, and consultation with general practitioners) suggest that osteoarthrosis makes a significant contribution to the handicap of manual workers. There was no significant difference in the prevalence rates between skilled and unskilled dockyard workers; this finding contrasts with the significantly higher rates for osteoarthrosis at all ages among coal miners working in awkward postures in confined spaces than among weight-lifting manual workers in other occupations. Direct observation and assessment of specific tasks support the hypothesis that posture may be more important than weight lifting as a risk factor in the onset of osteoarthrosis.
\end{abstract}

Key terms: disability, ergonomics, handicap, impairment, occupation, osteoarthrosis, sickness absence, weight lifting.

There is a body of opinion among British epidemiologists which supports the view that death as expressed in the form of the standardized mortality ratio is the most reliable measure of unmet health needs available at present - at least in the context of allocating resources among health authorities (4). Such a positivist attitude about the assessment of need is obviously unimpressive to those who are concerned with the care of patients suffering from chronically disabling but rarely fatal conditions. Among these are the musculoskeletal diseases, osteoarthrosis in particular, which seldom appears on a death certificate and is recorded as accounting for less than ten deaths per million in the population of England and Wales in contrast to such high rates per million as coronary thrombosis (3 117), malignancy $(2670)$, and chronic chest disorders (380) (13).

Morbidity statistics also tend to underrecord the prevalence of osteoarthrosis. One reason may be that the rubrics of the International Classification of Diseases (20) include many nonspecific rheumatic labels. Thus, in one study of general practice (12), the annual rate for registered patients with osteoarthrosis was recorded as 11 per 1000 of the population, whereas the total for musculoskeletal diseases as a whole was 91 per 1000 ; a similar study published 16 years earlier gave comparable figures (9).

1 Department of Community Medicine, United Medical and Dental Schools (Guy's Campus), London, the United Kingdom.

Reprint requests to: Prof JAD Anderson, Department of Community Medicine, UMDS (Guys), London Bridge, SE1 9RT, United Kingdom.
Even if general practitioners were able to make diagnoses with much greater precision, there would remain the difficulty of assessing the effects on the life-style of patients, or, in other words, the extent to which an affected person is occupationally disadvantaged as opposed to merely having an abnormality such as might be noted radiographically. It is only when the meaning of occupational disadvantage has been established that it can be considered reasonable to assess the size of the problem in terms of the extent of disruption to the workforce, identify the risk factors in relation to current knowledge of the pathological processes and their etiology, and suggest how these risk factors may be aggravated by work conditions. These are the issues which will be considered in this paper since their clarification is necessary before logical steps can be taken to modify the serious effects of arthrosis among the workforce by primary or secondary preventive measures and also to consider how best to manage established cases, including their rehabilitation.

\section{Disablement}

The four stages of disablement can be described as abnormality, malfunction, limitation of activity, and social disadvantage. In 1978 Wood \& Badley (19) suggested that malfunction and the limitation of activity should be merged under the heading of disability to give the three categories of impairment, disability and handicap. Subsequently, however, a working party of the World Health Organization (21), using similar terminology, agreed that malfunction 
should be merged with abnormality as impairment and the term disability should be reserved for limitation of activity. Table 1 shows how the presented classifications can be applied to osteoarthrosis of the knee.

Thus, in relation to osteoarthrosis, a person who has osteophytes demonstrable radiographically or who has been found on biopsy to have substandard cartilaginous lining of a joint may be said to be abnormal - although the fact that such changes may be observed in one or more joints in the majority of individuals over 50 years of age (5) renders even this concept open to challenge. Either of these findings could justify a diagnosis of osteoarthrosis, but in neither of the circumstances described would it be necessary for the affected individual to have any symptoms, let alone a limitation of activity; however clinical examination might show limited movement in the affected joint when compared with the contralateral one (malfunction). Such a situation would only

Table 1. Groupings in classifications of disablement by Wood \& Badley (19) and the World Health Organization (WHO) (21) and possible applications to osteoarthrosis of the knee.

\begin{tabular}{|c|c|c|c|}
\hline & $\begin{array}{l}\text { Wood \& } \\
\text { Badley }\end{array}$ & WHO & $\begin{array}{l}\text { Osteoarthrosis } \\
\text { of knee }\end{array}$ \\
\hline Abnormality & Impairment ) & & $\begin{array}{l}\text { Osteophytes in } \\
\text { radiograph } \\
\text { Changes seen in } \\
\text { biopsy }\end{array}$ \\
\hline Malfunction & ----- & Impairment & $\begin{array}{l}\text { Reduced flexion } \\
\text { on clinical } \\
\text { examination }\end{array}$ \\
\hline $\begin{array}{l}\text { Limitation } \\
\text { of activity }\end{array}$ & Disability & & $\begin{array}{l}\text { Difficulty with } \\
\text { stairs or kneeling }\end{array}$ \\
\hline $\begin{array}{l}\text { Social } \\
\text { disadvantage }\end{array}$ & Handicap & Handicap & $\begin{array}{l}\text { Inability to } \\
\text { work }\end{array}$ \\
\hline
\end{tabular}

amount to an impairment when the affected subject had loss of activity as, for instance, difficulty in climbing stairs or kneeling. Even then the extent to which the condition constituted a handicap would depend on the requirements of the individual. If such a limitation affected a coal miner, for instance, working at the coalface in the confined space of a narrow seam, then the handicap might well be total; however, if the disabled person merely wanted to be in charge of an occupational health research unit in a London Medical School, then the handicap could well be negligible.

Thus the key features of the disablement process are that an affected person may be unaware of an impairment whether structural or functional, while one with disability cannot perform as well as his or her peer group and that there is generally an awareness of this situation either by the person affected or by relatives of the person in infancy (also where there is concurrent brain damage or some other factor interfering with judgement). However such disability may cause little or no embarrassment since it is only when the limitation impinges directly on activity that the affected person wants to perform for occupational, recreational, or social purposes that a handicap is imposed. In other words, the question of whether or not an impairment or disability will lead to handicap depends not only on the physical condition, but also on intellectual, emotional, and social factors.

\section{Size of the problem}

In a series of prevalence studies of rheumatic complaints involving 2684 mixed manual workers aged 15 to 65 years from different occupations in the United Kingdom it was found that 1399 (52 \%) gave a history of musculoskeletal problems suggestive of

Table 2. Percentages of men who had treatment or periods of work absence due to osteoarthrosis (nodal and local) or vague pain in limb joints (2).

\begin{tabular}{|c|c|c|c|c|c|c|}
\hline \multirow[t]{2}{*}{ Indicators of handicap } & \multicolumn{2}{|c|}{$\begin{array}{l}\text { Nodal (general) } \\
\text { osteoarthrosis } \\
(\mathrm{N}=44)\end{array}$} & \multicolumn{2}{|c|}{$\begin{array}{l}\text { Localized } \\
\text { osteoarthrosis } \\
(N=149)\end{array}$} & \multicolumn{2}{|c|}{$\begin{array}{l}\text { Vague pain in } \\
\operatorname{limb} \text { joints } \\
(\mathrm{N}=215)\end{array}$} \\
\hline & $\mathbf{N}$ & $\%$ & $N$ & $\%$ & $\mathrm{~N}$ & $\%$ \\
\hline Self care during past year & 19 & 43.1 & 6 & 4.0 & 68 & 31.6 \\
\hline $\begin{array}{l}\text { Consulted general practitioner } \\
\text { during past year }\end{array}$ & 17 & 38.6 & 58 & 38.9 & 40 & 18.6 \\
\hline $\begin{array}{l}\text { Referred to hospital some time } \\
\text { in past }\end{array}$ & 13 & 29.5 & 46 & 30.9 & 26 & 12.1 \\
\hline $\begin{array}{l}\text { Admitted to hospital some time } \\
\text { in past }\end{array}$ & 2 & 4.5 & 7 & 4.7 & 4 & 1.4 \\
\hline $\begin{array}{l}\text { Subjective assessment of effect } \\
\text { on work }\end{array}$ & & & & & & \\
\hline $\begin{array}{l}\text { Nil } \\
\text { Moderate or severe }\end{array}$ & $\begin{array}{r}22 \\
8\end{array}$ & $\begin{array}{l}50.0 \\
18.2\end{array}$ & $\begin{array}{l}81 \\
33\end{array}$ & $\begin{array}{l}54.3 \\
22.1\end{array}$ & $\begin{array}{r}208 \\
13\end{array}$ & $\begin{array}{r}96.7 \\
0.6\end{array}$ \\
\hline $\begin{array}{l}\text { Sickness absence in past year } \\
\text { Persons absent } \\
\text { Days lost } t^{\mathrm{a}}\end{array}$ & $\begin{array}{r}6 \\
105\end{array}$ & 13.6 & $\begin{array}{r}28 \\
864\end{array}$ & 18.8 & $\begin{array}{r}8 \\
171\end{array}$ & 3.7 \\
\hline
\end{tabular}

a Days lost per year: nodal osteoarthrosis, localized osteoarthrosis, and vague pain caused a mean annual absence (days) per 100 affected men of $238.6,579.9$, and 79.5 , respectively. 
rheumatic complaints occurring at some time during their worklives. All these men were examined clinically, without recourse to radiography; the criteria used for the diagnosis have been given elsewhere (2). Joint changes indicative of osteoarthrosis were observed in 223 of the workers $(8 \%$ of the total sample). Fifty-nine ( $2 \%$ ) of the men had Heberden's nodes and were therefore described as having nodal or generalized osteoarthrosis.

In addition to the men for whom a diagnosis of osteoarthrosis was possible with reasonable certainty on clinical grounds, there were 295 with indeterminate pain in or around the joints of the limbs. Many of these workers might well have shown the stigmata of osteoarthrosis had radiography or biopsy techniques been feasible. On the other hand at least some of the indeterminate pain may, as in the case of the 478 men with vague pain in the back, have been due to disc disease since only those with demonstrable nerve root signs were allocated to this category.

As has already been discussed the prevalence of osteoarthrosis in a survey of this kind does not imply that all those so identified have a handicap. Therefore the various factors which might be taken to indicate handicap have been summarized in table 2 . Twenty-five out of $193(13 \%)$ of those with osteoarthrosis indulged in self-treatment during the year prior to examination, and 75 out of $193(39 \%)$ had a consultation with their general practitioners. Thirty-one percent of the men with osteoarthrosis had been referred to a hospital at some time in the past, and $5 \%$ had been admitted.

What is perhaps more important is the proportion who indicated subjectively that they felt disadvantaged in relation to work. In this respect two groups of osteoarthrosic subjects were similar; thus 103 men (53\% of those affected) had no problem, while 41 $(21 \%)$ indicated moderate to severe handicap in relation to their work. However, when sickness absence was studied, there was a marked difference between those with nodal osteoarthrosis and those with the more localized lesions. The nodal group recorded a mean annual absence of $239 \mathrm{~d}$ per 100 affected men, while the rate for the more localized forms was 580 $\mathrm{d}$, even though there was little difference in the mean ages of the two groups. As would be expected, the men with vague pain in the limb joints, pain which could not be identified definitely as osteoarthrosis, had fewer problems, and a much higher percentage $(97 \%)$ of these workers said that they had no interference with their work.

\section{Risk factors}

Secondary or localized osteoarthrosis was distinguished from the primary or generalized form by Kellgren \& Moore (10) more than 30 years ago. On balance the literature since that time has supported the idea that there is a genetic basis for Heberden's nodes, which is more pronounced in females than in males $(11,15)$. It also seems to be accepted that, at least to some extent, there is a genetic basis for development of many cases of more localized osteoarthrosis, over which the individual has little control (8). Furthermore, what is now known as osteoarthrosis has been regarded as a disease of the elderly (1) ever since the time of Hippocrates, and therefore the process is likely to come with advancing years regardless of any occupational hazard.

More recently discussions have been centering increasingly on biochemical changes and the genetic basis for these changes, while attempts to correlate osteoarthrosic changes in the hip with obesity have often produced unconvincing if not negative results (7). That does not mean to say that obese people may not be more handicapped by osteoarthrosis of the weight-bearing joints than are their lean counterparts but merely that the objective changes demonstrable by radiography, biopsy, or postmortem diagnosis appear to be dependent on factors other than the physical one of weight compression.

Superimposed on the evidence which supports inherent traits as the basis for the development of degenerative changes is also evidence suggesting that chronic irritation can, and often does, accelerate the process. These circumstances lead naturally to the concept that prolonged heavy work may do likewise. Wells (18) in his Rammazzini oration, discussed in general the "hard life of people who must work for a living," and this has given added zest to those seeking to identify certain occupational hazards as being risk factors, if not causal agents, of osteoarthrosis.

It seems likely that the development of degenerative changes can be triggered in those at risk by one or both of two mechanisms. The first is a sudden impact of great severity which in some way damages the cartilaginous lining of the joint (14). Evidence to support this theory has been obtained from cadaver specimens in which surface fissuring of the cartilage was shown to arise following high stress levels on impact. However, stresses of this magnitude are unlikely to be achieved in vivo except under circumstances akin to those caused by impact in a traffic accident or achieved by jumping from a height of around $5 \mathrm{~m}$. Neither of these circumstances applies generally to the majority of people who ultimately suffer from osteoarthrosis.

The other possibility is that stresses of a lesser order applied over a prolonged period may produce a situation of fatigue, as is well known to occur in metals (17). It would seem logical to argue that this possibility is more likely to occur when the pressure on the joint is such as to force the capillary layer of interarticular fluid from between the cartilaginous surfaces so that they may be in direct contact, and this situation must be maintained long enough to 
Table 3. Osteoarthrosis in manual workers in a coal mine and dockyard and craftsmen in a dockyard (2). $(\mathbf{N}=$ number of workers in group and \% = percentage of group with osteoarthrosis).

\begin{tabular}{|c|c|c|c|c|c|c|c|c|c|c|c|c|}
\hline \multirow{3}{*}{ Occupation } & \multicolumn{12}{|c|}{ Age group (years) } \\
\hline & \multicolumn{2}{|c|}{15} & \multicolumn{2}{|c|}{25} & \multicolumn{2}{|c|}{35} & \multicolumn{2}{|c|}{45} & \multicolumn{2}{|c|}{$55-64$} & \multicolumn{2}{|c|}{$15-64$} \\
\hline & $\mathbf{N}$ & $\%$ & $N$ & $\%$ & $\mathbf{N}$ & $\%$ & $\mathbf{N}$ & $\%$ & $\mathbf{N}$ & $\%$ & $N$ & $\%$ \\
\hline \multicolumn{13}{|l|}{ Face workers in a } \\
\hline $\begin{array}{l}\text { coal mine } \\
\text { General laborers in }\end{array}$ & 67 & 0 & 50 & 4.0 & 71 & 8.5 & 80 & 18.0 & 86 & 34.9 & 354 & 15.0 \\
\hline $\begin{array}{l}\text { a dockyard } \\
\text { Craftsmen in a dockyard }\end{array}$ & $\begin{array}{r}29 \\
232\end{array}$ & $\begin{array}{r}0 \\
0.4\end{array}$ & $\begin{array}{r}48 \\
171\end{array}$ & $\begin{array}{l}2.1 \\
2.9\end{array}$ & $\begin{array}{r}73 \\
181\end{array}$ & $\begin{array}{l}2.7 \\
3.3\end{array}$ & $\begin{array}{l}109 \\
247\end{array}$ & $\begin{array}{r}11.0 \\
9.3\end{array}$ & $\begin{array}{l}108 \\
221\end{array}$ & $\begin{array}{l}15.7 \\
12.7\end{array}$ & $\begin{array}{r}367 \\
1052\end{array}$ & $\begin{array}{l}8.7 \\
6.0\end{array}$ \\
\hline
\end{tabular}

Table 4. Job analysis of effort of legs and stance at work among 2684 male manual workers assessed by an independent observer and the standardized ratios for localized osteoarthrosis among these workers [Data of earlier report (2) reanalyzed for present review].

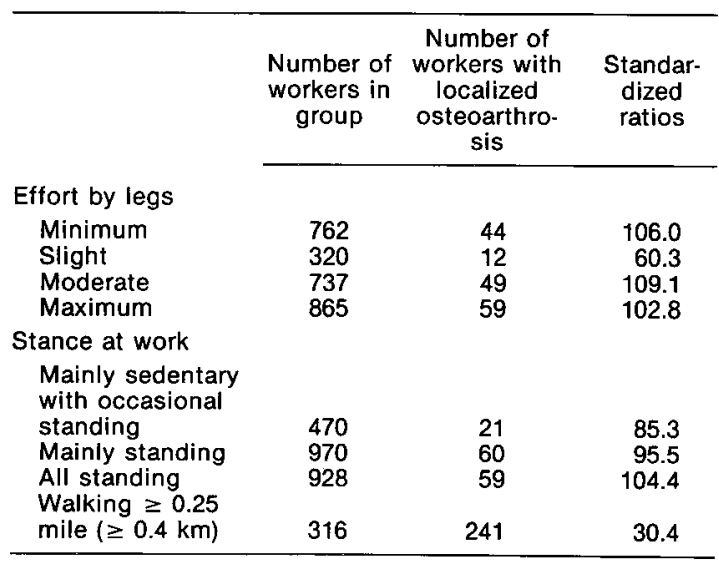

have a detrimental effect on the contact surfaces. Such a state of affairs can be shown to occur under laboratory conditions. It is likely that many activities associated with everyday living and occupation can lead to temporary compression sufficient to bring the two joint surfaces into direct opposition without any fluid intervening. However, if this situation is maintained for a long time (as for instance with heavy lifting or awkward posture), then the cartilage may be put at risk and the lesions associated with advancing years may develop.

Such a theory would also be in keeping with the long known tendency for osteoarthrosis to develop in joints which are in proximity to malaligned fractures (6). More important from the occupational point of view, the theory would be supported by the observations that the prevalence of osteoarthrosis in the facetal joints of the lumbar spine, as well as in the hips and knees, is higher among those engaged in heavy manual tasks than among those in lighter occupations (11).

Supportive evidence for at least part of the theory is available in the study of manual workers to which reference has already been made (2). The prevalence rate for osteoarthrosis in all age groups was higher among miners working at the coalface than among general laborers in other occupations (table 3) even though the latter were often required to move weights similar to those of their coal-mining counterparts. The difference appeared to be in relation to the postural requirements of the coalface, since the seam in the particular mine where this series of studies was based had a height of between 70 and $80 \mathrm{~cm}$, and thus considerable strain was put on the knees, hips, and ankles, as well as the backs, of the face workers. On the other hand it was not possible to demonstrate any significant difference in the prevalence rates for osteoarthrosis between unskilled dockyard workers and those engaged as skilled craftsmen in the same employment (table 3). Both groups were performing manual tasks though in general the skilled were not required to lift so many heavy weights as the unskilled and this difference was reflected in the slight increase in osteoarthrosis among the unskilled group over the age of 45 years.

Yet more evidence to support the view that posture may be more important than weight lifting was obtained from direct observations of all the workers performing their normal tasks. These observations had to be made individually since not everyone engaged in the same designated occupation did the same tasks. Indeed the components of a task may differ from one workshop to another, and individuals may adopt different postures in their performance of apparently identical tasks at the work bench or in other occupational circumstances (2).

One series of observations which was made of the 2684 male manual workers and which has special relevance to osteoarthrosis has been made in relation to the legs when jobs were assessed by an observer using a four-point scale based on demand for muscular effort (2). In the same study (2) a second series of scored observations was made of the stance and mobility at work. For the present report these observations were matched against the diagnosis of local osteoarthrosis previously made by a medical observer using a standardized technique to eliminate age bias. Table 4 shows the findings of the matching of these two series of observations. From them it is apparent that there is no obvious gradient between the standardized ratios for localized osteoarthrosis and the scores for effort, while there does appear to be a gra- 
dient for the standardized ratios in respect to increasing demands for mobility on the job.

These basic studies have paved the way for further work using techniques of continuous monitoring of limb movements (16) and posture (3). However, the difficulty is that, currently, priority appears to demand that observations of the back take precedence over those of osteoarthrosis. This situation is perhaps regretable since it could well be that significant steps forward might be made in relation to osteoarthrosis, and such progress may be more difficult to achieve in studies of the complexities of spinal movements.

\section{References}

1. Adams R. A treatise on rheumatic gout, or chronic rheumatic arthritis of all joints. Churchill, London 1857.

2. Anderson JAD. Rheumatism in industry: A review. $\mathrm{Br}$ J Ind Med 28 (1971) 103-121.

3. Anderson JAD. Occupational aspects of low back pain. Clin Rheum Dis 6 (1980) 17-35.

4. Bennett AE, Holland WW. Rational planning or muddling through: Resource allocation in the N.H.S. Lancet 1 (1970) 464-466.

5. Bennett GA, Waine H, Bauer W. Changes in the knee joint at various ages. The Commonwealth Fund, New York, NY 1942.

6. Bouler M. Fossilmen (translated by Ritchie J). Edinburgh 1923 .

7. Bullough PG, Goodfellow JW, O'Connor JJ. The relationship between degenerative changes and load bearing in the human hip. J Bone Jt Surg 55 B (1973)
$746-758$.

8. Carter CO. Genetics of common disorders. Br Med Bull 25 (1969) 52.

9. General Register Office. Morbidity statistics from general practice. Volume 1 (General). Her Majesty's Stationery Office, London 1958. (Studies on medical and population subjects no 14).

10. Kellgren JH, Moore R. Generalised osteoarthritis and Heberden's nodes. Br Med J 1 (1952) 181-187.

11. Lawrence JS. Rheumatism in populations. Heinemann, London 1977.

12. Office of Population Censuses and Surveys. Morbidity statistics from general practice: Second national study 1970-71. Her Majesty's Stationery Office, London 1974. (Studies on medical and population subjects no 26).

13. Office of Population Censuses and Surveys. Registrar General's statistical review for England for 1982. Her Majesty's Stationery Office, London 1984.

14. Repo RV, Finlay JB. Survival of articular cartilage after controlled impact. J Bone Jt Surg 59 A (1977) 1068-1076.

15. Solomon L, Beighton $\mathbf{P}$, Lawrence JS. Rheumatic disorders of the South African negro: Part II Osteoarthritis. S Afr Med J 49 (1975) 1737-1740.

16. Sweetman BJ. Low backpain, sickness absence and work factors. University of London, London 1980. (Doctoral thesis).

17. Weightman B. Tensile fatigue of human articular cartilage. J Biomech 9 (1976) 193-200.

18. Wells RL. The hard life of people who must work for a living. J Occup Med 11 (1969) 439—442.

19. Wood PHN, Badley EM. Setting disablement in perspective. Int Rehabil Med. 1 (1978) 32-37.

20. World Health Organization. International classification of diseases: 1975 revision. Geneva 1978.

21. World Health Organization. International classification of impairments, disabilities and handicaps. Geneva 1980. 